\title{
LAS ANTIHORMONAS
}

\author{
DR. D. M. GONZALES TORRES \\ De la Universidad de Asunción (Paräguay) y del Laboratorio Paulista de \\ Biologia.
}

Si inyectamos a un animal durante cierto tiempo una hormonat, llega un momento en que el animal no reacciona más, creándose un estado refractario, lo cual es debido a lá produccion en el ofgañismo animal, de una substancia inhibidora llamada antihormona por Collip.

Es un fenomeno analogo al que se pasa en la formacion de anticuerpos por inyeocion de antigenos. Si inyectamos por ej. extracto hipofisario tireotropo a un animal, producimos en él signos de irritacion tiroidea; continuando la inyeccion, llega un momento en que tal exitacion no se produce más; es como si el animal se volviera refractario a la inyeccion.

Esta' produccion de antihormona parece estar ligada al componente proteino de la hormona. Segun Collip y Anderson, no se puede determinar, la produccion de antihormonas con la inyeccion de hormona cristalizadas, y segun Collip solo con extracto hipofisario (extractos impuros con polipeptidos) es posible esa produccion, no siendo por lo tanto un fenomeno de orden general.

Sin embargo, Eitel y Loeser obtienen substancia antitireotropa por inyeccion de Tiroxina, y Bauer demostro ha poco, que tambien con Tiroxina, adrenalina y diiodotirosina se puede provocar la formacion de antihormonas no absolutamente especificas, puesto que un suero daba reaccion de complemento con los tres productos.

Bauer y otros (Schachter, Kunewalder) inyectando durante 6-7 semanas pequeñas dosis diarias de tiroxina a un cobayo, consiguen un estado de tiroxinoresistencia con formacion de una substancia antitiroxínica, y fuerte desvio de complemento en presencia de Tiroxina.

Collip y Anderson inyectan al caballo (cuyo suero no contiene previamente substancia inhibidora) durante seis semanas, $1.000 \mathrm{U}$. cobayo diarias de extracto tireotropo hipofisario, y obtiene un suero del que 0,4 ec previenen la accion de $100 \mathrm{U}$. de hormona tireotropa.

La inyeccion contemporanea a un cobayo, de hormona tireotropa y suero de animal tratado previamente ('es decir, con antihormonas) no permite la aparicion de un cuadro de hipertiroidismo ni modificaciones histológicas de la Tiroides: hay una verdadeira neutralizacion de la $\mathrm{h}$. tireotropa. 
Estas experiencias tueron repetidas por numerosos experimentadores con los mismos resultados. Bruner y Star llegaron a obtener del mismo modo sueros con poder inhibidor, mismo para dosis $200 \mathrm{v}$. más fuertes que las dosis iniciales. Blum y Laura separadamente, obtienen mediante la inyeccion al caballo de extracto hipofisario posterior, un suero que disminuye la glicosuria de los diabeticos. A este primer intento de produccion artificial de antihormona, han seguido otros, experimentando con ovario (Cotte), testiculo (Wiese), etc....

En las experiencias con antihormona tiroidea', el metabolismo basal no sufre modificaciones posteriores con la inyeccion de extracto tireotropo (una vez creado este éstado de resìstencia), en cambio sí lo es por la inyeccion de tiroxina. (La ensibilidad a la tiroxina cuando hay una inmunidad para la $h$. tireotropa demostraria la accion sobre la hipofisis).

Si a un animal sin preparacion inyectamos suero antitireotropo (es decir con antihormonios) y luego tiroxina, el M. B. se eleva sin ninguna atenuacion:

Ambas experiencias prueban que el suero con antihormonio actúa inhibiendo directamente la hormona tireotropa y nó la tiroxina.

Pero aún hay más; la substancia antitiroidea se produce mismo en animales tiroidectomizados y mismo hipofisectomizados. C. Foa piensa que puede ser la suprarrenal (que contiene cortina, y ac. ascorbico, substancias conocidamente antitiroideas) - la responsable de la formacion de la substancia antitireotropa.

Las mismas conclusiones se obtienen experimentando çon extracto gonatropo (Collip y Anderson, en 1934), somatotropo, adrenotropo. Parkes y Rowlands en 1936, inyectan diariamente durante largo tiempo a una coneja, extracto hipofisario gonadotropo de buey, y obtienen después de 10 semanas un suero que, inyectado a otra coneya normal impide la ovulacion, y crea un estado refractario a dosis mismo muy fuertes de h. gonadotropa. Este suero antigonadotropo alcanzaba su maximo de actividaded tres meses después del comienzo de las inyecciones de extracto hipofisario.

Estos mismos autores, y varios otros, demonstraron tambien que existen sueros antihormonios para substancias gonadotropas de origen hipofisario, tal como para las extrahidas de la orina, suero, placenta, de mujeres gravidas.

La antihormona es substancia inestable, que se destruye por calentamiento prolongado a $100^{\circ}$, soluble en alcohol y eter, absorbible, y que precipita por acetona a $92 \%$ (C. Foá).

Collip y su escuela creen que es una substancia normal en el suero, que ya existe encubierta en el organismo, y necesaria para la regulacion normal endocrina.

Otłos niegan su preexistencia, y C. Foá afirma: "no es que las antihormonas no existen, sino que se producirian luego de la inyeccion de préparados hormonicos parcialmente desnaturados del proceso de extraccion". Es por esso que las antihormonas son generadas solamente por hormonas de natureza proteica o de extractos aún 
no suficientemente purificados y conteniendo proteinas. Se obtienen resultados más rapidos usando extractos brutos que un extracto' de estimulina purificada.

Parece que no existe especificidad zoologica por lo menos en lo que se refiere a antihormona tireotropa, pues que con hormorra tireotropa de caballo se puede obtener en un buey, antihormonas capaces de actuar en animal de otra especie.

Conclusiones práticas: por lo que antecéde, podemos explicarnos los fracasos después de cierto tiempo del uso de ciertos extractos opoterapicos, sobre todo en sindromes hipofisarios;

durante un tratamiento opoterapico, es prudente usar fases de reposo. Aunque no se ha demonstrado lo mismo en el hombre, en el animal los antihormonios se eliminan en 1.2 meses;

es preferible usar extractos muy purificados, que tienen poco poder antigénico;

se plantea la posibilidad por lo menos teórica, del tratamiento. con suero de animales preparados y ricos en antihormonios. En este punto, los resultados no han sido lo que se esperaba, aunque sea prematuro afirmar categoricamente algo definitivo.

\section{BIBLIOGRAFIA}

Collip, Anderson - Lancet. 1,76,226,784. 1934.

Parkes, Rowlands - J. Physiol. 88,305, 1937. Lancet. 17-IV-37.

C. FoÁ - Evoluzione dei concetti sulle secrezione interne e sulla correlazione umorale. Tratt. di Endocrin. Milano, 1939.

P. Rambert - Le probléme des antihormones. Paris Médical. 22-IV-39. 